\title{
Naked Exclusion and the Anticompetitive Accommodation of Entry
}

\author{
Julian Wright*
}

September 2006

\begin{abstract}
We model exclusive dealing when the incumbent and potential entrant offer differentiated products and buyers are downstream firms. While the resulting exclusive dealing is always anticompetitive, it does not necessarily involve foreclosure.
\end{abstract}

\section{Introduction}

The existing naked exclusion literature focuses on the ability of an established firm to write exclusive deals with consumers to deny an entrant the necessary scale to profitably enter (Rasmusen et al., 1991 and Segal and Whinston, 2000). In this paper, a model is developed in which such exclusive deals are feasible, but in which the incumbent may do better by only signing exclusive deals with some buyers, thereby allowing its rival the necessary scale to enter. However, these exclusive deals remain anticompetitive, raising prices and lowering welfare by limiting downstream competition for the rival's product.

The model we employ has two essential differences from the standard models of naked exclusion. First, we allow the incumbent and entrant to offer differentiated products. Entrants often compete by appealing to a segment of customers or offering distinct product features. Second, recognizing that exclusive deals almost never involve final consumers, we follow Fumagalli and Motta (2006) by assuming buyers are downstream firms that compete amongst themselves for final consumers. ${ }^{1}$

To highlight the new strategic effect we identify, consider the case the entrant has only modest fixed costs of entry, so that it can profitably enter even if just one buyer is available. This case naturally arises when downstream firms are homogenous, so for instance, attracting one retailer is enough for a manufacturer to attract the whole market. If all other buyers sign with the incumbent, a buyer that deviates and does not sign gets profits from the fact it is the sole seller of the entrant's (unique) product. This makes compensating buyers for signing exclusively with the incumbent more expensive. It also makes accommodating entry more attractive, since the incumbent will enjoy greater demand for its product given the final price of the entrant's good is high when the entrant has only one seller of its

\footnotetext{
* Corresponding author. National University of Singapore: email jwright@nus.edu.sg

${ }^{1}$ See also Simpson and Wickelgren (2004) and Abito and Wright (2006). These works assume upstream firms offer identical products and either obtain that exclusive deals are never offered since any signed buyer gets driven out of the market (Fumagalli and Motta), or if the signed buyer is always present, that exclusive deals lead to foreclosure, as happens in this paper when products are sufficiently homogeneous.
} 
good. As a result, when products are sufficiently differentiated, we find that the incumbent will allow the rival to enter by not signing all downstream firms, and instead profits from the softening of downstream competition for the rival's product. On the other hand, when products are not much differentiated, this strategic effect is weak and the incumbent does better by signing up all downstream firms, excluding the entrant, and raising industry profits. In either case, exclusive deals are anticompetitive.

The paper provides another example of how firms may exploit a strategic effect arising from vertical restraints, thereby softening competition. Unlike the strategic effects of exclusive territories (as in Rey and Stiglitz, 1988, 1995), where an upstream firm commits its downstream firm to be less competitive, here the incumbent uses exclusive deals to directly raise the price of the rival's good. Our model also differs from some raising rivals' cost explanations of exclusive dealing. For instance, Comanor and Frech (1985) assume exclusive deals directly raise the entrant's cost of distributing its product through alternative channels which allows the incumbent to foreclose entry, rather than by raising the entrant's distribution margin which they take as exogenous.

The rest of the paper proceeds as follows. Section 2 presents the model while Section 3 presents the main results.

\section{The model}

For convenience, we will refer to upstream firms as manufacturers and downstream firms as retailers. Consider an incumbent manufacturer (denoted $I$ ) and a potential entrant (denoted $E$ ) that produce differentiated products. The incumbent proposes exclusive contracts to $N \geq 2$ retailers in the initial stage which the retailers either accept or reject. This exclusive contract involves the incumbent offering some fixed compensation $x$ to retailers in return for them agreeing not to purchase from the entrant. Let $S$ denote the number of retailers that sign the exclusive contract $(S=0,1, \ldots, N)$. To avoid open-set problems in defining equilibria, we assume that when retailers are indifferent between signing a contract and not, they sign the contract. Retailers that sign are called "signed retailers" while those that do not are called "free retailers".

After observing the retailers' decisions on whether to sign these contracts, the entrant makes its entry decision. In the third stage, the manufacturer(s) set wholesale prices to each retailer, which can depend on whether a retailer signed the initial contract or not. To highlight that our results do not rely on a strategic effect through wholesale prices, we assume each retailer cannot observe the wholesale prices charged to its rivals. ${ }^{2}$ In the final stage, retailers compete for consumers.

For simplicity, both manufacturers are assumed to face the same production cost (constant marginal $\operatorname{costs} c$ ) and face symmetric demand for their products. The entrant faces a fixed cost of entry equal to $F>0$. Retailers are homogenous and compete in prices. This means the retail price of a particular product is determined by that of the cheapest retailer that carries the product. If all retailers set the same price for a particular product, they are assumed to share its demand equally. The costs of retailing is normalized to zero.

\footnotetext{
${ }^{2}$ With observable offers, the results are very similar.
} 


\section{Anticompetitive accommodation and exclusion}

To determine the relative incentives for the incumbent to accommodate or exclude, we make some general assumptions on the nature of demand and how product differentiation impacts the profits of the different types of firms. Let $p_{I}$ and $p_{E}$ denote the retail prices of the incumbent's and entrant's products respectively. We write the demand for the incumbent' product as $q\left(p_{I}, p_{E}\right)$, which has the standard properties (see Singh and Vives, 1984, Section 5). By symmetry, the demand for the entrant's product can be written $q\left(p_{E}, p_{I}\right)$. Restricting attention to prices where both products attract positive demand, we assume $q\left(p_{I}, p_{E}\right)$ is decreasing in $p_{I}$, increasing in $p_{E}$, and that the price that maximizes $\left(p_{I}-w\right) q\left(p_{I}, p_{E}\right)$ is increasing in $w$ and $p_{E}$. The symmetric properties are true of the entrant's demand.

The demand function $q$ is assumed to be parameterized by $\gamma$ between 0 and 1 , which determines how homogenous or differentiated the products are. The higher $\gamma$, the more homogenous the two products are. In the limit as $\gamma \rightarrow 1$, the products become identical (perfect substitutes), while as $\gamma \rightarrow 0$ the products become maximally differentiated (independent goods). Suppose throughout $0<\gamma<1$.

If the incumbent enjoys a monopoly position, selling through identical competing retailers, wholesale prices will be determined as if manufacturers are selling directly to final consumers. Let $\Pi_{M}=$ $\left(p_{M}-c\right) q\left(p_{M}, \infty\right)$ denote the corresponding monopoly profit, where $p_{M}$ is the standard monopoly price. When manufacturers instead compete, each selling through identical competing retailers, the same logic implies the profits of manufacturers can be defined as $\Pi_{D}=\left(p_{D}-c\right) q\left(p_{D}, p_{D}\right)$, where $p_{D}$ is the standard duopoly price. We restrict attention to the case $0<F \leq \Pi_{D}$, since otherwise the rival manufacturer will not enter even absent exclusive dealing.

We make two additional assumptions.

A1 When the rival manufacturer does not enter, the incumbent's monopoly profit $\Pi_{M}$ is continuous and non-decreasing in $\gamma$.

A2 When the rival manufacturer enters, the equilibrium profits of the manufacturers and retailers are continuous and non-increasing in $\gamma$.

If the demand for a product offered in the absence of a rival product can be separated from the degree of product differentiation, then monopoly profit will not depend on $\gamma$ and $A 1$ holds. This is true for the standard linear demands model with a representative consumer, in which the inverse demand for firm $i$ can be written as

$$
p_{i}=\alpha-\beta\left(q_{i}+\gamma q_{j}\right) .
$$

$A 1$ also holds for the standard Hotelling specification of product differentiation with unit demands, in which firm $i$ 's demand is

$$
q_{i}=\frac{1}{2}+\frac{p_{j}-p_{i}}{2 t}
$$

in which lower transport costs make products more homogenous ( $t$ is inversely related to $\gamma$ ) and increase $\Pi_{M}$.

In contrast to $A 1$, assumption $A 2$ pertains to the profits of firms when both manufacturers compete. Clearly $A 2$ holds for retailers when multiple free retailers compete. Then identical retailers obtain zero 
profit in equilibrium regardless of $\gamma$ (consistent with A2). Moreover, the incumbent and entrant face a pricing game equivalent to that of a standard symmetric duopoly. Assumption $A 2$ then just requires the usual property that equilibrium duopoly profits are continuous and non-decreasing in the degree of product differentiation. When there is just one free retailer, the manufacturers' equilibrium profits will be different from those of standard duopolists since the entrant's product will be subject to double marginalization whereas the incumbent's product will not. $A 2$ assumes product differentiation still has its normal qualitative effect on equilibrium profits of each of the players. As confirmed in Wright (2006), this property turns out to be satisfied with the linear demands in (1), as well as with the standard Hotelling unit demands in (2).

With these assumptions, the role of exclusive deals is determined in the following proposition.

Proposition 1 If fixed costs of entry are sufficiently low and product differentiation is sufficiently strong, all but one retailer will sign with the incumbent and the rival manufacturer will enter. Such exclusive deals will raise the price of both manufacturers' products and (with elastic demand) lower welfare. With higher fixed costs of entry or weaker product differentiation, exclusive deals will be used to foreclose entry leading to monopoly prices and no choice for consumers.

Proof. First consider the different subgames according to how many retailers $I$ signs up. If $I$ signs up $N-2$ or fewer retailers, then there will be two or more retailers competing for each manufacturer's product. The equilibrium price that results is $p_{D}$, with each manufacturer obtaining profit $\Pi_{D}$ and each retailer obtaining zero profit. Given the assumption $0<F \leq \Pi_{D}$, this allows enough profit for $E$ to enter. If $I$ signs up all $N$ retailers, then $E$ cannot sell its product and $I$ will enjoy a monopoly position. The equilibrium price that results is $p_{M}$, with $I$ obtaining profit $\Pi_{M}$ and each retailer obtaining zero profit.

The case that remains is when $I$ signs up exactly $N-1$ retailers. If $E$ enters, it can only sell through the one remaining free retailer. Since two or more retailers compete to sell $I$ 's product, it will sell to them at a common wholesale price $w$. The signed retailer(s) obtain zero profit. The single free retailer also makes no profit selling $I$ 's product. However, the free retailer is a monopoly seller of $E$ 's product. It sets a price $p_{E}$ to maximize its profit $\left(p_{E}-w_{E}\right) q\left(p_{E}, p_{I}\right)$. The result is a profit maximizing price $p_{E}\left(w_{E}, p_{I}\right)>w_{E}$ that is increasing in $w_{E}$ and $p_{I}$. Since $p_{I}=w_{I}$, the incumbent sets $w_{I}$ to maximize $\left(w_{I}-c\right) q\left(w_{I}, p_{E}\right)$ while $E$ sets $w_{E}$ to maximize $\left(w_{E}-c\right) q\left(p_{E}\left(w_{E}, p_{I}\right), p_{I}\right)$. Let $\Pi_{I}$ and $\Pi_{E}$ denote the resulting profits for $I$ and $E$ in equilibrium, and let $\pi_{f}$ denote the profit of the free retailer in equilibrium. Note $\pi_{f}>0$. If we fix the price of $I$ 's good $p_{I}$ at the duopoly level $p_{D}$, the free retailer's best response is to set a price greater than $p_{D}$ given that $w_{E}>c$. This increases the demand for I's product. Given $I$ always has the option of setting $w_{I}=p_{D}$, it follows therefore that $\Pi_{I}>\Pi_{D}$. In contrast, $\Pi_{E}$ can be higher or lower than $\Pi_{D}$. Given $F \leq \Pi_{D}$, we therefore need to consider the following two cases.

(1) If $F>\Pi_{E}, E$ will only enter if it can attract two or more retailers. However, it is a dominant strategy for retailers to sign with $I$ for any positive compensation since retailers obtain zero profits if they remain free regardless of what other retailers do. Given our tie-breaking rule, $I$ will exclude by setting $x=0$, which gives it the monopoly profits $\Pi_{M}$. 
(2) If instead $F \leq \Pi_{E}, E$ will enter even if it can only attract one retailer. $I$ then faces two choices. It can exclude by signing up all retailers, offering each retailer its deviation profit $\pi_{f}$ in compensation. This gives $I$ profit of $\Pi_{M}-N \pi_{f}$. Alternatively, $I$ can sign up all but one retailer, thereby accommodating E. Given that one retailer is free, all other retailers will be willing to sign for an arbitrarily small compensation (if they also do not sign, then they will obtain zero profit in the retail market). Given our tie-breaking rule, $I$ can get these $N-1$ retailers to sign by setting $x=0$, which gives it a profit of $\Pi_{I}$. Therefore, $I$ has to choose between signing up all $N$ retailers and getting $\Pi_{M}-N \pi_{f}$ or signing up $N-1$ retailers and getting $\Pi_{I}$. (Signing up no retailers results in a profit of $\Pi_{D}$, which is lower than $\Pi_{I}$ from the result above).

Consider the difference between I's profit under the two different strategies as a function of $\gamma$, which we write as $\Delta(\gamma)=\Pi_{M}-N \pi_{f}-\Pi_{I}$. Consider first $\gamma \rightarrow 1$. In this case, $\Pi_{M}$ takes on its maximal value from $A 1$. If $E$ enters, both manufacturers will compete wholesale prices down towards marginal cost, resulting in $\Pi_{I} \rightarrow \Pi_{D} \rightarrow 0$, and $\pi_{f} \rightarrow 0$. Together, these results imply $\Delta(\gamma) \rightarrow \Pi_{M}>0$ for $\gamma$ sufficiently close to 1 . On the other hand, as $\gamma \rightarrow 0, I$ faces independent demand so that $\Pi_{I} \rightarrow \Pi_{D} \rightarrow \Pi_{M}$. Moreover, $\pi_{f}$ remains bounded from below at some positive level (the profit of a monopoly retailer selling an independent product), implying $\Delta(\gamma)<0$ for $\gamma$ sufficiently close to 0 . Since $A 1$ and $A 2$ imply $\Delta(\gamma)$ is continuous and non-decreasing in $\gamma$, for any $N$, there exists a critical level of product differentiation $0<\gamma_{N}<1$ such that $I$ signs up all retailers for $\gamma>\gamma_{N}$, and signs up only $N-1$ retailers for $\gamma \leq \gamma_{N}$.

This implies when product differentiation is sufficiently strong, $I$ does better accommodating entry by signing only $N-1$ retailers, while when product differentiation is sufficiently weak, $I$ does better excluding by signing all $N$ retailers and foreclosing the market. When $I$ accommodates entry by signing $N-1$ retailers, we showed above the prices of both products will be higher compared to duopoly prices $p_{D}$ without exclusive dealing. With elastic demand, welfare will be lower. When $I$ signs all retailers, $E$ stays out, leading to monopoly prices and no choice for consumers.

Proposition 1 demonstrates that the incumbent will always sign up retailers in anticompetitive exclusive deals. Either it signs up sufficient retailers to deter entry altogether, or it accommodates the rival's entry but limits intrabrand competition for the entrant's good, thereby making it a soft competitor. Which strategy the incumbent chooses depends on the rival's fixed costs of entry, the strength of upstream competition and the number of downstream competitors.

If the rival's fixed costs of entry are relatively high, so that the entrant requires access to a competitive retail market to profitably enter, then the entrant will always be excluded. Getting a share of the incumbent's monopoly profits is always preferred by retailers than obtaining nothing under intense retail competition.

When the fixed costs of entry are lower and the entrant only needs a single retailer to sell its product to profitably enter, there are then two scenarios to consider depending on the strength of upstream competition. If the manufacturers' products are similar, strong upstream competition will limit the ability of a deviating retailer to make much profit from being the sole seller of the entrant's product. Low retail profits make it relatively cheap for the incumbent to bribe the retailer to sign, hence increasing the share of the monopoly profits the incumbent can keep when it signs up all retailers. The result is the 
entrant is still excluded.

If, on the other hand, manufacturers' products are strongly differentiated, a deviating retailer benefits a lot from being the sole distributor of the entrant's good. Although it may still be feasible, the incumbent no longer finds it worthwhile to bribe each of the retailers to sign. Rather, the incumbent does better by saving on compensation, allowing the entrant to enter, and benefiting from the elimination of retail competition for the rival's product. This raises the retail price of the rival's good, and so the demand for the incumbent's good. In this case, the incumbent deliberately chooses to accommodate entry by signing up all but one retailer, leaving the entrant with no downstream competition for its good. This strategy is cheap since it costs the incumbent nothing to sign up retailers who know they cannot obtain any profit selling the entrant's product, given at least one other identical retailer will already choose to do so.

The choice of accommodation versus entry also depends on the number of retailers in the downstream market. When the entrant only needs one retailer to profitably enter, signing up retailers to exclude an entrant is expensive since each retailer has to be compensated for the profit it could obtain by deviating and being the entrant's sole retailer. The more retailers there are, the more expensive foreclosure becomes.

Proposition 2 Assuming the entrant only needs one retailer to profitably enter, anticompetitive accommodation of entry (rather than foreclosure) becomes more likely (that is, holds for lower levels of product differentiation) as the number of retailers increases.

Proof. Given retailers are identical price competitors, manufacturers' equilibrium profits do not depend on the number of retailers in the market, as long as there are two or more. This means that $I$ 's profit from foreclosing the market decreases in the number of retailers, as the number of retailers it has to compensate by offering $\pi_{f}$ increases. In contrast, its profit from accommodating $E$ by signing up only $N-1$ retailers (without compensation) remains constant. As a result, the critical level of $0<\gamma_{N}<1$ is increasing in $N$, so that $I$ will accommodate entry for a larger range of $\gamma$ when $N$ is higher.

Turning Proposition 2 around, we can determine the critical number of retailers $N(\gamma)$ necessary for the incumbent to prefer to accommodate entry for a given level of product differentiation. Using the linear demand specification in (1), we find $\Pi_{M}=(\alpha-c)^{2} / 4 \beta, \Pi_{D}=\psi /(2-\gamma)^{2}, \Pi_{I}=\psi(4+3 \gamma)^{2} /\left(8-3 \gamma^{2}\right)^{2}$ and $\pi_{f}=\psi(2+\gamma)^{2} /\left(8-3 \gamma^{2}\right)^{2}$, where $\psi=(1-\gamma)(\alpha-c)^{2} / \beta(1+\gamma)$. These profit functions satisfy $A 1$ and $A 2$. Solving for $N(\gamma)$ gives

$$
N(\gamma)=\frac{\gamma\left(32+12 \gamma-12 \gamma^{2}+9 \gamma^{3}+9 \gamma^{4}\right)}{4(1-\gamma)(2+\gamma)^{2}}
$$

For example, if $\gamma=0.5$ the incumbent will always sign all retailers to foreclose the market, while if $\gamma=0.75$, it will only foreclose if there are no more than four retailers. As products become homogenous $(\gamma \rightarrow 1)$, the incumbent prefers to foreclose the market by signing up all retailers, even if there are large numbers of them.

If the incumbent chooses to allow entry, the incumbent will offer an arbitrarily small compensation to ensure not all retailers will want to sign up. With simultaneous and non-discriminatory contracts, it is not clear how retailers will coordinate to ensure all but one sign, especially since the retailer that does not sign obtains higher profits in equilibrium. The incumbent can avoid a potential coordination failure 
by using discriminatory contracts. It can offer compensation to all but one retailer. However, unlike the analysis in Rasmusen et al. (1991) and Segal and Whinston (2000), discriminatory (or sequential) offers do not change the compensation the incumbent must offer.

Exclusive deals are always anticompetitive in this model (they reduce the total amount of competition and raise prices). Banning exclusive deals unambiguously raises welfare in the case the incumbent accommodates entry since the only effect of exclusive deals is to reduce downstream competition and raise retail prices. Foreclosure, however, could be efficient if there is excessive entry under duopoly in the sense of Mankiw and Whinston (1986). This is possible in the Hotelling specification of demand in (2) but not for the linear demand case given by (1).

\section{References}

Abito, J. M. and J. Wright (2006) "Exclusive dealing with imperfect downstream competition," mimeo, National University of Singapore.

Comanor, W.S. and H.E. Frech III (1985) "The competitive effects of vertical agreements?," American Economic Review, 75: 539-546.

Fumagalli, C. and M. Motta (2005) "Exclusive dealing and entry, when buyers compete," American Economic Review, 96: 785-795

Mankiw, N.G. and M.D. Whinston (1986) "Free entry and social inefficiency," RAND Journal of Economics 17: 48-58.

Rasmusen E.B., J.M. Ramseyer, and J.J.S. Wiley (1991) "Naked exclusion," American Economic Review 81: $1137-45$.

Rey, P. and J.E. Stiglitz (1988) "Vertical restraints and producers' competition," European Economic Review 32: 561-568.

Rey, P. and J.E. Stiglitz (1995) "The role of exclusive territories in producers' competition," RAND Journal of Economics 26: 431-451.

Segal, I. and M.D. Whinston (1996) "Naked exclusion: Comment," American Economic Review 90: 296-309.

Simpson, J. and A. L. Wickelgren (2004) "Naked exclusion, efficient breach, and downstream competition," mimeo.

Singh, N. and X. Vives (1984) "Price and quantity competition in a differentiated duopoly," RAND Journal of Economics, 15: 546-554.

Wright, J. (2006) "Naked Exclusion and the Anticompetitive Accommodation of Entry: Two Examples," mimeo, National University of Singapore. 